\title{
Effect of Soybean Cyst Nematode Resistance Source and Seed Treatment on Population Densities of Heterodera glycines, Sudden Death Syndrome, and Yield of Soybean
}

Yuba R. Kandel, Department of Plant Pathology and Microbiology, Iowa State University, Ames 50011; Kiersten A. Wise, ${ }^{\dagger}$ Department of Botany and Plant Pathology, Purdue University, West Lafayette, IN 47907; Carl A. Bradley, Department of Plant Pathology, University of Kentucky, Princeton 42445; Martin I. Chilvers, Adam M. Byrne, Department of Plant, Soil and Microbial Sciences, Michigan State University, East Lansing 48824; Albert U. Tenuta, Ontario Ministry of Agriculture, Food, and Rural Affairs, Ridgetown, ON N0P2C0, Canada; Jamal Faghihi, Department of Entomology, Purdue University, West Lafayette, IN 47907; and Stith N. Wiggs, and Daren S. Mueller, Department of Plant Pathology and Microbiology, Iowa State University, Ames 50011

\begin{abstract}
A three-year study was conducted in Illinois, Indiana, Iowa, Michigan, and Ontario, Canada, from 2013 through 2015 to determine the effect of soybean (Glycine max) cultivars' source of soybean cyst nematode (SCN; Heterodera glycines) resistance on SCN population densities, sudden death syndrome (SDS; caused by Fusarium virguliforme), and yield of soybean. Five cultivars were evaluated with and without fluopyram seed treatment at each location. Cultivars with no SCN resistance had greater SDS severity, greater postharvest SCN egg counts $(\mathrm{Pf})$, and lower yield than cultivars with plant introduction (PI) 548402 (Peking) and PI 88788-type of SCN resistance $(P<0.05)$. Cultivars with

Peking-type resistance had lower Pf than those with PI 888788-type and no SCN resistance. In two locations with HG type 1.2-, cultivars with Peking-type resistance had greater foliar disease index (FDX) than cultivars with PI 88788-type. Fluopyram seed treatment reduced SDS and improved yield compared with a base seed treatment but did not affect SCN reproduction and $\operatorname{Pf}(P>0.05)$. FDX and Pf were positively correlated in all three years $(P<0.01)$. Our results indicate that SDS severity may be influenced by SCN population density and HG type, which are important to consider when selecting cultivars for SCN management.
\end{abstract}

Soybean cyst nematode (SCN; Heterodera glycines Ichinohe) and sudden death syndrome (SDS), caused by Fusarium virguliforme O'Donnell and T. Aoki (Aoki et al. 2003), are two major constraints of soybean (Glycine max (L.) Merr.) production across North America (Wrather et al. 2010). These pathogens have been reported from most soybean-producing states throughout the United States (Hartman et al. 2015a; Tylka and Marett 2014). Estimated losses of U.S. soybean production from 2012 to 2014 due to damage caused by SCN and SDS ranged from 4.0 to 5.1 million metric tons, with an average of 4.5 million metric tons annually (Bradley et al. 2014). Fusarium virguliforme can infect soybean seedling roots shortly after seed germination, causing root rot and reduced root mass (Hartman et al. 2015b). Foliar SDS symptoms usually appear around beginning pod (R3 growth stage; Fehr et al. 1971) as chlorotic mottling and necrosis between leaf veins that progresses to premature defoliation, leaving the petioles attached (Hartman et al. 2015b; Roy et al. 1997).

Soybean cyst nematode feeds on soybean roots. Visual symptoms, though often not present, may appear in patches when soybean is under stress or SCN infestation is severe. Symptomatic plants can be stunted and yellow, and can mature early. These symptoms can easily be confused with several other disorders and diseases. Soybean cyst nematode can cause up to $30 \%$ yield losses without exhibiting visible symptoms (Wang et al. 2000).

Management of each pathogen is difficult since no effective management options are available after planting. Resistance to SDS is multigenic, and to date, no one gene or quantitative trait locus confers complete resistance. Management of each pathogen may also be complicated by the presence of the other because $F$. virguliforme

\section{${ }^{\dagger}$ Corresponding author. E-mail: kawise@purdue.edu}

*The $\boldsymbol{e}$-Xtra logo stands for "electronic extra" and indicates that three supplementary tables are published online.

Accepted for publication 4 July 2017.

(c) 2017 The American Phytopathological Society and SCN are frequently observed in the same field. Currently, rotation with nonhost crops and use of resistant soybean cultivars are the two primary management strategies for SCN (Niblack 2005). There are currently only two sources of SCN resistance that commonly are used to breed soybean cultivars: plant introductions (PI) 88788 and PI 548402 (Peking) (Tylka and Mullaney 2015). PI 88788 is the most widely used source of SCN resistance and is in the majority of commercially available cultivars (Concibido et al. 2004; Faghihi et al. 2008; Tylka and Mullaney 2015). However, the continuous use of PI 88788 has led to a genetic shift in virulence of the SCN populations and SCN reproduction on PI 88788 is increasing (Acharya et al. 2016; Faghihi et al. 2008; Hershman et al. 2008; Mitchum et al. 2007; Rzodkiewicz 2010; Wise et al. 2016; Zheng et al. 2006). Soybean cyst nematode populations can be characterized by their reproduction on soybean indicator lines with different sources of $\mathrm{SCN}$ resistance, to designate $\mathrm{SCN}$ populations to $\mathrm{HG}$ (H. glycines) types (Niblack et al. 2002). The HG type test is a greenhouse test that determines how well a SCN population reproduces on the sources of resistance used to develop soybean cultivars (Niblack et al. 2002). Research has demonstrated that less effective SCN resistance can lead to greater yield losses from SDS, when both are present in a field (Marburger et al. 2013). Knowing the HG type of a $\mathrm{SCN}$ population in a field helps in developing an effective management plan.

Interactions between SDS and SCN have been documented with both positive and negative associations (Marburger et al. 2013; McLean and Lawrence 1993; Melgar et al. 1994; Powell 1971; Roy et al. 1989; Scherm et al. 1998; Xing and Westphal 2006). For example, McLean and Lawrence (1993) reported that foliar symptoms of SDS appeared a week earlier and were more severe when coinoculated with $F$. virguliforme and $\mathrm{SCN}$ than with $F$. virguliforme inoculation alone. However, in some studies, $\mathrm{SCN}$ presence played minimal or no role in SDS development (Gao et al. 2006; Scherm et al. 1998). The potential for increased yield losses due to the presence of both pathogens warrants additional research, and it is important to understand how a shifting SCN population affects $F$. virguliforme infection, development of SDS foliar symptoms, and soybean yield. 
Fluopyram (ILeVO; Bayer CropScience, Research Triangle Park, NC) was registered as a seed treatment fungicide for SDS management in 2014. Fluopyram, a succinate dehydrogenase inhibitor (Fungicide Resistance Action Committee group 7), reduced SDS and increased yield in several locations (Kandel et al. 2016a, b). Fluopyram also suppressed SCN reproduction in greenhouse studies (Beeman and Tylka 2015; Zaworski 2014). The fluopyram fungicide seed treatment label (Bayer CropScience website) indicates that this fungicide also controls several important nematodes in soybean production systems in addition to $H$. glycines. However, this product has not been evaluated for SCN management in wide-scale public field trials.

The objectives of this study were to determine how SCN resistance source and seed treatment affect SCN population densities, SDS development, and yield.

\section{Materials and Methods}

A total of 18 field experiments were conducted from 2013 through 2015 in seven locations in Illinois, Indiana, Iowa, Michigan, and Ontario, Canada (Table 1). Planting dates ranged from late April to early June across locations. Experimental plots varied in size, consisting of four rows with inter-row spacings of 38.1 to $76.2 \mathrm{~cm}$ and row lengths of 5.3 to $9.1 \mathrm{~m}$. Each plot served as an experimental unit. All experiments were established in a randomized complete block design with four to eight replicates. In 2013, five cultivars with different levels of SDS resistance and differing SCN resistance sources were used. Specific cultivars differed across locations and were selected based on availability and site adaptation (Supplementary Table 1). However, each experiment had cultivars that derived resistance from Peking and PI 88788 sources of resistance and a cultivar with no known SCN resistance that served as a control. The term "source" throughout the remainder of the manuscript refers to the source of SCN resistance. Cultivars ranged from moderately susceptible to moderately resistant to SDS. In 2014 and 2015, experiments were expanded including two seed treatments (base seed treatment as control and base seed treatment plus fluopyram) to determine if fluopyram complements SCN host resistance, as previously indicated in greenhouse trials (Zaworski 2014) and arranged as a randomized complete block design with factorial arrangements. The base seed treatment consisted of prothioconazole + penflufen + metalaxyl (EverGol Energy), metalaxyl (Allegiance), and clothianidin + Bacillus firmus (Poncho/VOTiVO) from Bayer CropScience. EverGol Energy, Allegiance, and Poncho/VOTiVO were applied at 0.019, 0.02 , and $0.13 \mathrm{mg}$ a.i./seed, respectively. The fluopyram treatment included fluopyram at $0.15 \mathrm{mg}$ a.i./seed, in addition to the base seed treatment described above. Seeds were treated using a Hege bowl seed treater (Wintersteiger, Salt Lake City, UT). Pro-Ized red seed colorant (Gustafson LLC, Plano, TX) and finisher (Peridiam Precise 1010, Bayer CropScience) were added to the treated seed at a rate of $32.6 \mathrm{ml} / 100 \mathrm{~kg}$ and $65 \mathrm{ml} / 100 \mathrm{~kg}$ seed, respectively.

In each location and year, experiments were conducted in fields with a history of both SCN and SDS. Also, experiments were infested with $F$. virguliforme-colonized sorghum all years at planting except in Iowa, Michigan, and Ontario in 2013 (Table 1). The sorghum infested with $F$. virguliforme was combined with soybean seed immediately prior to planting in each seed envelope following the rate given in Table 1 . The seed was dropped through the planter into the cone and the soybean seed was planted along with the $F$. virguliforme infested sorghum. Where infested, $F$. virguliforme inocula were prepared from locally originated, single-spore-generated pure cultures following previously published protocols (de Farias Neto et al. 2006; $\mathrm{Li}$ et al. 2009). Natural infestations of SCN were relied upon for all field experiments.

Fields were cultivated before planting, and the previous crop was corn (Zea mays L.) or soybean in all locations. Experimental plots in Illinois, Indiana, and Michigan were irrigated in all years and those in Iowa were irrigated in 2014 and 2015. All other site-years received natural precipitation only. Irrigation details are provided in Table 1. Recommended soybean production practices, including herbicide application, planting population, and nutrient management, were

Table 1. Experiment locations and field activities performed in Iowa, Illinois, Indiana, Michigan, and Ontario, Canada, from 2013 through 2015

\begin{tabular}{|c|c|c|c|c|c|c|c|c|c|c|c|}
\hline \multirow[b]{2}{*}{ Year } & \multirow[b]{2}{*}{ Location } & \multirow{2}{*}{$\begin{array}{c}\text { Planting } \\
\text { date }\end{array}$} & \multirow{2}{*}{$\begin{array}{c}\text { Harvest } \\
\text { date }\end{array}$} & \multicolumn{2}{|c|}{ SDS rating } & \multirow[b]{2}{*}{ Inoculation $^{w}$} & \multirow[b]{2}{*}{ Previous crop } & \multirow[b]{2}{*}{ Irrigation $^{x}$} & \multicolumn{2}{|c|}{$\begin{array}{c}\text { Sampling date } \\
\text { for } \mathrm{SCN}^{\mathbf{y}}\end{array}$} & \multirow{2}{*}{$\begin{array}{l}\text { Initial } \\
\text { SCN }^{z}\end{array}$} \\
\hline & & & & Date & Growth states $^{v}$ & & & & Initial & Postharvest & \\
\hline \multirow[t]{6}{*}{2013} & Ames, IA & 23 May & $24 \mathrm{Sep}$ & 4 Sep & R6.4 to R7.0 & No & Corn & No & 23 May & $24 \mathrm{Sep}$ & 1,113 \\
\hline & Urbana, IL & 15 May & 14 Oct & 30 Aug & R6.2 & Yes & Soybean & Yes & 15 May & & 1,036 \\
\hline & Wanatah, IN & 8 May & $10 \mathrm{Oct}$ & 6 Sep & R6.0 & Yes & Corn & Yes & $\ldots$ & $14 \mathrm{Nov}$ & $\ldots$ \\
\hline & Decatur, MI & 1 May & 8 Oct & 16 Aug & R6.0 & No & Corn & Yes & 1 May & 4 Oct & 6,213 \\
\hline & Highgate, ON & 17 May & $21 \mathrm{Oct}$ & $6 \mathrm{Sep}$ & R6.0 to R6.2 & No & Corn & No & 11 May & 21 Oct & 2,726 \\
\hline & Rodney, ON & 17 May & 23 Oct & 27 Aug & R6.0 to R6.2 & No & Corn & No & 12 May & 23 Oct & 4,476 \\
\hline \multirow[t]{6}{*}{2014} & Ames, IA & 6 May & 6 Oct & $8 \mathrm{Sep}$ & R6.0 to R6.4 & Yes & Corn & Yes & 6 May & 6 Oct & 183 \\
\hline & Urbana, IL & 6 May & $12 \mathrm{Oct}$ & 27 Aug & R6.0 to R6.2 & Yes & Soybean & Yes & $\ldots$ & NA & $\ldots$ \\
\hline & Wanatah, IN & 3 Jun & $3 \mathrm{Nov}$ & 28 Aug & R5.5 & Yes & Corn & Yes & 5 Jun & $13 \mathrm{Nov}$ & 131 \\
\hline & Decatur, MI & 6 May & $1 \mathrm{Oct}$ & 26 Aug & R6.0 to R7.0 & No & Corn & Yes & 6 May & 13 Oct & 1,596 \\
\hline & Highgate, ON & 27 May & $23 \mathrm{Oct}$ & 27 Aug & R6.0 to R6.2 & No & Corn & No & 27 May & 30 Oct & 3,674 \\
\hline & Rodney, ON & 30 May & $30 \mathrm{Oct}$ & $3 \mathrm{Sep}$ & R6.0 to R6.2 & No & Corn & No & 30 May & $6 \mathrm{Nov}$ & 3,345 \\
\hline \multirow[t]{6}{*}{2015} & Ames, IA & $29 \mathrm{Apr}$ & $22 \mathrm{Sep}$ & 27 Aug & R5.8 to R6.0 & Yes & Corn & Yes & $29 \mathrm{Apr}$ & $22 \mathrm{Sep}$ & 933 \\
\hline & Decatur, IL & 3 May & 16 Oct & $21 \mathrm{Aug}$ & $\mathrm{R} 6.0$ & Yes & Soybean & Yes & 2 May & 23 Sep & 13 \\
\hline & Wanatah, IN & 28 May & 19 Oct & $14 \mathrm{Sep}$ & R6.0 to R7.0 & Yes & Corn & Yes & 5 Jun & 20 Oct & 4 \\
\hline & Decatur, MI & 1 May & $2 \mathrm{Oct}$ & 20 Aug & R6.0 & No & Corn & Yes & 4 May & $6 \mathrm{Oct}$ & 3,536 \\
\hline & Highgate, ON & 11 May & 2 Oct & $2 \mathrm{Sep}$ & R6.0 to R6.2 & No & Corn & No & 11 May & 2 Oct & 2,393 \\
\hline & Rodney, ON & 15 May & $13 \mathrm{Oct}$ & $7 \mathrm{Sep}$ & R6.0 to R6.2 & No & Corn & No & 15 May & $13 \mathrm{Oct}$ & 2,877 \\
\hline
\end{tabular}

v Foliar symptoms of sudden death syndrome (SDS) were rated on R5 to R7 soybean growth stages (GS) according to the Fehr et al. (1971).

${ }^{\mathrm{w}}$ Experimental plots were inoculated at planting using sorghum seed infested with locally originated Fusarium virguliforme isolates in Iowa, Illinois, and Indiana. In Iowa, isolate $N E 305$, at $8.3 \mathrm{~g} / \mathrm{m}$ of linear row; Illinois, isolate $M o n t-1$, at $4.1 \mathrm{~cm}^{3} / \mathrm{m}$ of linear row; Indiana, a mixture of three isolates collected locally ( $N R R L$ 22823, 00-11-183, and INS12-10 \#3-1), at $8.3 \mathrm{~g} / \mathrm{m}$ of linear row were applied.

$\mathrm{x}$ Water was delivered through drip irrigation in Illinois and in Iowa (second and third year) and through overhead irrigation in Indiana and Michigan. In Illinois, irrigation was started in June and ran every week for 6 weeks; each week, about $2.5 \mathrm{~cm}$ of water was delivered. In Iowa, irrigation was started in the first week of August and ran six times at 1-week intervals; about $2.5 \mathrm{~cm}$ of water was delivered each time. In Indiana, between the growth stages V5 and R5, approximately $2.5 \mathrm{~cm}$ of water was delivered through overhead irrigation in weeks when natural precipitation did not occur. In Michigan, up to $2.5 \mathrm{~cm}$ of water was applied per week starting from emergence to R5.

y "..." samples were not taken; "NA" = Date was not available.

${ }^{z}$ Initial soybean cyst nematode (SCN): Average number of $\mathrm{SCN}$ eggs/100 $\mathrm{cm}^{3}$ soil recorded in spring (prior to or right after planting). 
followed for each location as outlined within each state's Extension recommendations.

Initial and postharvest $\mathrm{SCN}$ population densities. To determine SCN population densities, initial and postharvest soil samples were collected within 20 days after planting and within a month of harvesting, respectively (Table 1). Depending on location, six to 10 soil cores were collected with a soil probe of $2.5 \mathrm{~cm}$ diameter to a depth of 20 to $30 \mathrm{~cm}$ in each plot using a "W" pattern. Postharvest samples were collected from the soybean root zone. Soil samples were stored at $4{ }^{\circ} \mathrm{C}$ until SCN egg extraction. Each soil sample was thoroughly mixed, then $100 \mathrm{~cm}^{3}$ soil was subsampled immediately before SCN extraction was performed. SCN cysts isolated from soil using mechanical agitation, and wet sieving and decanting as outlined by Gerdemann (1955) and a protocol developed by Faghihi and Ferris (2000) was followed to release eggs from cysts. Egg counts were used to calculate the reproductive factors (Rf), or change in nematode population over the season, using the following formula: $\mathrm{Rf}=\mathrm{Pf} / \mathrm{Pi}$; where $\mathrm{Pf}=$ postharvest $\mathrm{SCN}$ egg counts and $\mathrm{Pi}=$ initial SCN egg counts (Wang et al. 2000; Brucker et al. 2005).

HG typing. HG typing (Niblack et al. 2002) was performed on the SCN populations from all locations in 2015. Samples remaining from each plot after subsampling $100 \mathrm{~cm}^{3}$ for Pf were bulked and used for HG typing. Samples from Indiana, Iowa, and Ontario were HG typed by the Plant Nematology Laboratory at the University of Missouri (Columbia, MO). The SCN populations from Illinois and Michigan were typed by the University of Illinois Plant Clinic (Urbana, IL), and the Diagnostic Services at Michigan State University (East Lansing, MI), respectively. HG type is based on female index (FI) values, which are the percentage of SCN reproduction on an HG type indicator line (source of resistance) relative to that on a susceptible line (Table 2). The FI is calculated as follows: $(\mathrm{N} 1 / \mathrm{N} 2) \times 100$; where $\mathrm{N} 1$ is the mean number of females reproduced on an HG type indicator line and $\mathrm{N} 2$ is the mean number of females on the standard susceptible soybean line, Lee 74 . The HG type designation includes the number for the indicator lines on which the FI is $10 \%$ or more. For example, HG type 1.2- means that the SCN population had FI equal or greater than $10 \%$ for indicator lines 1 (PI 548402 or Peking), 2 (PI 88788), but less than $10 \%$ in others (Niblack et al. 2002). The dash after the type designation numbers indicates that the HG test did not include a complete set of indicator lines, only those most commonly used to breed commercial soybean cultivars. A complete HG typing test includes seven indicator lines: (i) PI 548402 (Peking); (ii) PI 88788; (iii) PI 90763; (iv) PI 437654; (v) PI 209332; (vi) PI 89772; and (vii) PI 548316 (Cloud). Samples from Illinois, Indiana, Iowa, and Highgate and Rodney, ON, were tested on the standard seven indicator lines; however, Michigan samples were only tested on three indicator lines, most commonly used to breed commercial soybean cultivars. Thus, for consistency, we reported the HG type result based on the three indicator lines (HG indicator lines 1, 2, and 4) tested for all locations. The complete HG type test results for each location are provided in Supplementary Table 2.

Foliar SDS assessment. Experiments were assessed for foliar SDS symptoms multiple times during the season. In all locations, SDS symptoms were recorded between growth stages R5 and R7 (Fehr et al. 1971) from the middle two rows of each plot (Table 1). Disease incidence was recorded as the percentage of plants exhibiting foliar SDS symptoms. Foliar severity was based on the average disease severity of symptomatic plants per plot on a 1 to 9 scale where $1=1$ to $10 \%$ leaf surface chlorotic or 1 to $5 \%$ necrotic and $9=$ premature plant death, as previously described (Gibson et al. 1994; Kandel et al. 2015a). These data were used to derive the foliar disease index (FDX): FDX $=$ disease incidence $\times($ foliar severity/9).

Yield data. Experiments were harvested when plants reached harvest maturity (R8; Fehr et al. 1971), which was between late September and early November (Table 1). The two center rows from each plot that were on 78.2-cm row spacing and four rows for the plots that were on 38.1-cm row spacing of each plot were harvested mechanically, using a small-plot combine. Grain yield and moisture were recorded while harvesting, and grain yield was adjusted to $13 \%$ moisture.
Environmental data. Cumulative monthly precipitation and soil temperatures at planting were obtained from the weather stations installed near the experimental locations or from stations located closest to each experimental site using public weather service websites (http:// mesonet.agron.iastate.edu; http://Iclimate.org; http://yourweatherservice. com) (Supplementary Table 3). Soil temperatures were collected from a 10 -cm depth.

Data analysis. To determine how HG type influenced the effect of SCN resistance to dependent variables, experimental locations were grouped for analysis by HG type. Experiments were categorized in three groups based on the HG type test results and locations within a group were combined for analysis: (i) HG type 0-included Rodney, ON; (ii) HG type 2- included Illinois, Indiana, and Michigan; and (iii) HG type 1.2- included Iowa and Highgate, ON.

Analysis of variance was performed using Proc GLIMMIX (SAS version 9.4 (SAS Institute Inc., Cary, NC)) for FDX, grain yield, Pf, and Rf. Pf data were transformed using a square root transformation prior to analysis, and back-transformed means are presented. Yield reduction was calculated as follows: $((\mathrm{Y} 2-\mathrm{Y} 1) / \mathrm{Y} 2) \times 100$, where $\mathrm{Y} 1=$ yield produced by cultivars with no known source of resistance and $\mathrm{Y} 2=$ yield produced by cultivars with $\mathrm{SCN}$ resistance. SCN resistance source and seed treatment were considered fixed-effect factors, whereas experiment locations and replication within locations were considered random factors in the model. Correlations among FDX, yield, and Pf were analyzed using Pearson's correlation coefficient (Proc CORR).

\section{Results}

Initial SCN populations. Soybean cyst nematode was present in all experimental locations (Table 1). Initial SCN egg counts ranged from 1,036 to 6,213 , from 131 to 3,674 , and from 4 to 3,536 eggs per $100 \mathrm{~cm}^{3}$ in the spring of 2013,2014, and 2015, respectively. The greatest initial egg counts were observed in Decatur, MI, in 2013 and 2015, and in Highgate, ON, in 2014 (Table 1).

HG types. All SCN populations, except those from Rodney, ON, had FI values greater than $10 \%$ on PI 88788 (HG type indicator line 2) (Table 2). The highest FI on PI 88788 was $68 \%$ in Indiana. The FI values of SCN populations from Iowa and Highgate, ON also exceeded $10 \%$ on Peking (HG type indicator line 1). The FI values were below $10 \%$ on PI 437654 (HG indicator line 4) for all SCN populations. We reported the HG type result based on the three indicator lines (HG indicator lines 1, 2, and 4) tested for all locations. The Rodney, ON population was designated as HG type 0 -, that had FI $<10 \%$ on both PI 88788 and Peking, while Illinois, Indiana, and Michigan populations were designated as HG type 2- that reproduced on PI 88788 with $>10 \%$ FI (HG indicator line 2). The Iowa and Highgate, ON populations were HG type 1.2 - that reproduced on both Peking and PI 88788 with $>10 \%$ FI (HG indicator lines 1 and 2). None of the SCN populations had FI of at least 10\% on PI 437654 (HG indicator

Table 2. Female index (FI) values (\%) on HG type indicator lines for Heterodera glycines virulence phenotypes in 2015

\begin{tabular}{lcccc}
\hline & \multicolumn{4}{c}{ Indicator line } \\
\cline { 2 - 5 } Locations & $\begin{array}{c}\text { 1 = PI 548402 } \\
\text { (Peking) }\end{array}$ & $\begin{array}{c}\mathbf{2 =} \text { PI } \\
\mathbf{8 8 7 8 8}\end{array}$ & $\begin{array}{c}\mathbf{4 =} \mathbf{\text { PI }} \\
\mathbf{4 3 7 6 5 4}\end{array}$ & $\begin{array}{c}\text { HG } \\
\text { type }^{\mathbf{y}}\end{array}$ \\
\hline Illinois & $2^{\mathrm{z}}$ & 27 & 0 & $2-$ \\
Indiana & 1 & 68 & 0 & $2-$ \\
Iowa & 20 & 48 & 0 & $1.2-$ \\
Michigan & 1 & 31 & 0 & $2-$ \\
Highgate, ON & 14 & 30 & 0 & $1.2-$ \\
Rodney, ON & 9 & 9 & 0 & $0-$ \\
\hline
\end{tabular}

${ }^{y} \mathrm{HG}$ type describes the type of SCN population in that experiment site. HG type was assigned according to the indicator number on which FI is 10 or greater.

${ }^{\mathrm{z}}$ FI was calculated as follows: $(\mathrm{N} 1 / \mathrm{N} 2) \times 100$, where $\mathrm{N} 1$ is the number of females produced by the soybean cyst nematode $(\mathrm{SCN})$ population on the $\mathrm{HG}$ type indicator line and N2 is the number of females on the standard SCNsusceptible line (Lee 74). 
line 4). Based on these findings, experiments were grouped based on HG type and experiments with each group were combined for further analysis.

Effect of SCN resistance source on FDX and yield. Effect of SCN resistance source on FDX was influenced by the HG type present at the experimental locations (Table 3). FDX levels on PI 88788type and Peking-type resistance were not statistically different in all three years for the location with HG type 0-. In locations with HG type 2-, Peking-type resistance had lower FDX than PI 88788-type and the cultivars with no SCN resistance in 2014, but in 2013 there was no difference in FDX between Peking-type and PI 88788-type resistance. Effect of SCN resistance source on FDX was not significant in $2015(P=0.06)$. In locations with HG type 1.2-, FDX was significantly affected by SCN resistance source in all three years. FDX was lower on Peking-type and PI 88788-type resistance compared with no SCN resistance source in 2013 and 2014. However, in 2015 the FDX on Peking-type resistance was not statistically different from the FDX on no SCN resistance source and had almost double FDX than on PI 88788-type resistance. There were no differences in FDX between PI 88788-type and Peking-type resistance in 2013 and 2014 in locations with HG type 1.2-. Across locations, cultivars with no SCN resistance source had, in most cases, significantly greater FDX than with those with Peking-type and PI 88788-type resistance.

The SCN resistance source significantly affected yield $(P<0.05)$ in all locations, except in HG type 1.2- in $2014(P=0.29$, Table 3$)$. Cultivars with no SCN resistance source had the lowest yield in all locations. Overall, the yield difference between cultivars with and without known SCN resistance was greater in HG type 0- location than in other locations. In this location in 2013, cultivars with no SCN resistance source resulted in 56 and $49 \%$ less yield than cultivars with PI 88788-type and Peking-type resistance, respectively. In 2014 and 2015, a 25\% yield difference was observed between cultivars with no SCN resistance source versus cultivars with SCN resistance. In locations with HG type 2-, no SCN resistance source resulted in 13, 15, and $8 \%$ less yield than PI 88788-type resistance and 20, 23, and 10\% less than Peking-type resistance in 2013, 2014 , and 2015, respectively. In locations with HG type 1.2-, no significant yield differences were observed between PI 88788-type and Peking-type resistance in any year, but both produced greater yield than no SCN resistance source in 2013 and 2015.

Effect of SCN resistance source on $\mathrm{Pf}$ and Rf. SCN resistance source significantly affected $\mathrm{Pf}$ for all locations and years except in locations with HG type 0- in 2013 and 2014 (Table 4). In the HG type 0 - location, the effect of SCN resistance was significant in 2015 only. In locations where effect of SCN resistance was significant, Pf were lowest in plots with Peking-type resistance and highest in plots with no SCN resistance source. In 2013, Pf were similar in plots with no SCN resistance source and PI 88788-type, but the Pf were reduced in Peking-type resistance in HG type 2- locations. However, in 2014 and 2015, Pf was lowest in plots with Peking-type resistance and highest in plots with no SCN resistance source and intermediate in plots PI 88788-type resistance at all locations except the HG type 0 - location in 2014 (Table 4).

$\mathrm{SCN}$ reproduction was greater in plots with no $\mathrm{SCN}$ resistance source in most locations (Table 4). The net increase of the SCN egg counts in no SCN resistance source plots ranged from 2.2 to 14.threefold. The effect of SCN resistance source on Rf was significant in 2015 in the HG type 0 - location $(P<0.01)$. In 2015 , plots with no SCN resistance source had greater Rf than the plots with SCN resistance. In the HG type 0- location, although the HG type test reported 9\% FI on PI 88788-type resistance, the Rf of 2.1 resulted in an increase in SCN egg counts in the field. In HG type 2- locations, $\mathrm{Rf}$ on Peking-type resistance showed no net increase in SCN while no SCN resistance source and PI 88788-type resistance had increased SCN in all three years. Peking-type resistance reduced initial SCN numbers in $2013(\mathrm{Rf}=0.1)$, and $2014(\mathrm{Rf}=-0.2)$ in these locations. In locations with HG type 1.2-, the Rf was $>1.0$ on both PI 88788 type and Peking-type resistance. The plots with no SCN resistance source had greater Rf than those with PI 88788-type and Pekingtype resistance (Table 4). Pf were not different among years in all HG type groups (data not shown).

Effect of seed treatment on FDX, yield, Pf, and Rf. In 2015, fluopyram reduced FDX by $29 \%$ compared with the base seed treatment $(P=0.02)$. However, in 2014 , seed treatment effect on FDX was not significant (Table 5). Fluopyram seed treatments resulted in significantly greater yield, which was $6 \%$ more than base seed treatment in both years (Table 5). Seed treatment did not have a significant effect on Pf and Rf in either year (Table 5). Interactions of seed treatment-by-source of SCN resistance were not significant $(P>0.05)$ for any measured variables for both years.

Correlations between FDX and other variables. FDX and Pf were positively correlated in all three years $(P<0.01$, Table 6$)$. Pearson's correlation coefficients $(r)$ for FDX versus Pf were 0.31 for 2013 $(n=125)$ and $2014(n=250)$, and 0.18 for $2015(n=246)$. Yield was negatively correlated with FDX and with Pf for all three years $(P=<0.01)$. The correlation coefficients between yield and FDX ranged from -0.23 to -0.52 in the three years of the study. Pearson's correlation coefficients for yield versus Pf ranged from -0.35 to -0.40 (Table 6). The number of observations (n) used to correlate yield to FDX was 150 in 2013 and 250 in 2014 and 2015, and $n$ used to correlate yield to Pf was 125 in 2013 and 250 in the other two years.

Table 3. Main effects of soybean cyst nematode resistance (SCN Res) source for foliar sudden death syndrome index (FDX) and soybean yield in field experiments, grouped by HG type, performed in Illinois, Indiana, Iowa, Michigan, and Ontario, Canada in 2013, 2014, and 2015

\begin{tabular}{|c|c|c|c|c|c|c|c|}
\hline \multirow[b]{3}{*}{ Year } & \multirow[b]{3}{*}{ Source of SCN Res } & \multicolumn{3}{|c|}{ FDX $^{\mathbf{y}}$} & \multicolumn{3}{|c|}{ Yield (kg/ha) } \\
\hline & & \multicolumn{3}{|c|}{ HG Type group ${ }^{z}$} & \multicolumn{3}{|c|}{ HG Type group } \\
\hline & & 0- & $2-$ & $1.2-$ & 0- & $2-$ & $1.2-$ \\
\hline \multirow[t]{4}{*}{2013} & None & 0.1 & $33.1 \mathrm{a}$ & $0.3 \mathrm{a}$ & $783 \mathrm{~b}$ & $3,063 \mathrm{~b}$ & $3,441 b$ \\
\hline & PI 88788 & 0.1 & $8.1 \mathrm{~b}$ & $0.0 \mathrm{~b}$ & $1,761 \mathrm{a}$ & $3,539 \mathrm{ab}$ & $3,950 \mathrm{a}$ \\
\hline & Peking & 0.0 & $14.7 \mathrm{~b}$ & $0.0 \mathrm{~b}$ & $1,532 \mathrm{a}$ & $3,809 \mathrm{a}$ & $4,118 \mathrm{a}$ \\
\hline & $P$-value & 0.79 & $<0.01$ & $<0.01$ & $<0.01$ & 0.01 & $<0.01$ \\
\hline \multirow[t]{4}{*}{2014} & None & $13.5 \mathrm{a}$ & $12.5 \mathrm{a}$ & $20.4 \mathrm{a}$ & $2,217 \mathrm{~b}$ & $2,841 \mathrm{c}$ & 3,675 \\
\hline & PI 88788 & $4.7 \mathrm{~b}$ & $4.2 \mathrm{~b}$ & $8.0 \mathrm{~b}$ & 3,417 a & $3,327 \mathrm{~b}$ & 3,937 \\
\hline & Peking & $2.7 \mathrm{~b}$ & $0.1 \mathrm{c}$ & $13.4 \mathrm{ab}$ & $3,611 \mathrm{a}$ & $3,678 \mathrm{a}$ & 3,751 \\
\hline & $P$-value & $<0.01$ & $<0.01$ & $<0.01$ & $<0.01$ & $<0.01$ & 0.29 \\
\hline \multirow[t]{4}{*}{2015} & None & $6.8 \mathrm{a}$ & 12.0 & $33.0 \mathrm{a}$ & $3,993 \mathrm{~b}$ & $3,120 \mathrm{~b}$ & $2,674 \mathrm{~b}$ \\
\hline & PI 88788 & $1.2 \mathrm{~b}$ & 5.9 & $11.9 \mathrm{~b}$ & $5,530 \mathrm{a}$ & $3,409 \mathrm{a}$ & $3,758 \mathrm{a}$ \\
\hline & Peking & $1.5 \mathrm{~b}$ & 8.9 & $24.0 \mathrm{a}$ & $5,659 \mathrm{a}$ & $3,459 \mathrm{a}$ & $3,569 \mathrm{a}$ \\
\hline & $P$-value & $<0.01$ & 0.06 & $<0.01$ & $<0.01$ & 0.04 & $<0.01$ \\
\hline
\end{tabular}

$\overline{\mathrm{y}}$ FDX of SDS was calculated as follows: FDX = disease incidence $\times$ disease severity/9. Disease incidence was estimated as percentage of plants with sudden death syndrome symptoms per plot and disease severity was scored on a 1 to 9 scale $(1=1$ to $10 \%$ leaf surface chlorotic or 1 to $5 \%$ necrotic and $9=$ premature death) based on percentage of the chlorotic and necrotic leaf area and defoliation.

z Test locations were grouped based on HG type and locations within each group were combined for analysis. 
Weather variation and its effect on FDX and SCN. Supplemental Table 2 presents cumulative precipitation from 2013 through 2015 and 30-year average precipitation for each month during the growing seasons. Precipitation pattern varied across the three years of the experiment. In general, the growing season in 2013 was drier than 2014 and 2015 across all locations except in MI. Year to year difference for FDX was significant for all locations groups $(P \leq 0.05)$. FDX was lower in 2013 compared with 2014 and 2015 except in HG type 2locations, where experimental locations were provided with supplemental irrigation.

\section{Discussion}

In our three-year study relating SCN resistance source and HG type to FDX, yield, and SCN population, we determined that SCN resistance source influenced SDS development across a broad geographic area. Cultivars with no SCN resistance source had a greater FDX than cultivars with either PI 88788- or Peking-type resistance. Hershman et al. (1990) also reported that cultivars that were susceptible to SCN had higher SDS than SCN-resistant cultivars. The positive correlation between Pf and FDX in our study is supported by previous studies (McLean and Lawrence 1993; Xing and Westphal 2006; Xing and Westphal 2013). Previous reports (McLean and Lawrence 1993; Roy et al. 1989) also reported that SCN presence quickened the incidence and severity of SDS. Previous studies suggested that SCN increases plant stress, providing an avenue for fungal infection (Tabor et al. 2003; Tabor et al. 2006). Tatalović (2014) reported that SCN infection stimulates production of lateral roots, which are the primary infection sites for $F$. virguliforme. Therefore, conditions that favor SCN may also favor infection by $F$. virguliforme. However, some previous studies suggest either no association or negative association between SDS and SCN populations (Gao et al. 2006; Hershman et al. 1990; Scherm et al. 1998). The inconsistency suggests that the interaction is complex, and several factors such as SCN population density at the beginning of the season, environmental conditions, soil $\mathrm{pH}$, soil moisture, soil fertility, $F$. virguliforme inoculum concentration in the field, and cultivar susceptibility to both pathogens may affect the interaction.

In the HG type test, SCN populations reproduced, resulting in over $10 \%$ FI on cultivars with PI 88788-type resistance in most of the experimental locations. This suggests the development of a broad geographical breakdown of this source, supporting previous reports across the Midwest (Acharya et al. 2016; Faghihi et al. 2008; Hershman et al. 2008; Mitchum et al. 2007; Rzodkiewicz, 2010; Wise et al. 2016; Zheng et al. 2006). Although the FI on Peking was less than $10 \%$ for the SCN population in Illinois, Indiana, Michigan, and Rodney, ON, SCN populations from Iowa and Highgate, ON, reproduced with $>10 \%$ FI on both Peking and PI 88788, as determined by the type test, indicating that populations across the region are diverse.
Although cultivars with no SCN resistance were the lowest yield producers at all locations, the yield improvement by implementing SCN resistance was greatest in locations with HG type 0-, where SCN populations FI was $<10 \%$ on PI 88788 and Peking. Yield response by SCN resistance in the other locations where SCN could reproduce on PI 88788 and/or Peking with FI $>10 \%$ was lower than the HG type 0- locations, suggesting that where SCN populations are able to break the resistance source, SCN caused yield losses. In locations where PI 88788 was not effective at reducing SCN populations, Peking cultivars resulted in greater yield in at least one year. However, in fields where SCN was able to reproduce on both Peking and PI 88788, FDX was greater on Peking, despite having low SCN populations. This is in contrast to another study that indicated that Peking cultivars have lower FDX in areas where the SCN population can reproduce on PI 88788 and Peking (Wise et al. 2016). The influence of SCN resistance source on SDS in this study is difficult to elucidate, and the influence of variation in cultivars, environmental conditions, and other soil factors across locations cannot be ruled out. We did plant cultivars with a range of partial resistance to SDS for all sources of SCN resistance, but cultivars with the same SDS rating scale were not available for each $\mathrm{SCN}$ resistance source

Table 5. Main effects of seed treatment for sudden death syndrome (SDS) foliar disease index (FDX), soybean yield, postharvest soybean cyst nematode $(\mathrm{SCN})$ eggs (Pf) and SCN reproductive factor ( $\mathrm{Rf})$ as determined by combining all field experiments performed in Illinois, Indiana, Iowa, Michigan, and Ontario, Canada, in 2013, 2014, and 2015

\begin{tabular}{llcccl}
\hline Year & Seed treatment & FDX & Yield (kg/ha) & Pf $^{\mathbf{y}}$ & $\mathbf{R f}^{\mathbf{z}}$ \\
\hline 2014 & Base & 8.6 & 3,317 & 2,806 & 9.3 \\
& Base + Fluopyram & 8.5 & 3,509 & 2,945 & 7.3 \\
& $P$-value & 0.93 & 0.02 & 0.68 & 0.73 \\
2015 & Base & 14.9 & 3,510 & 1,741 & 2.8 \\
& Base + Fluopyram & 10.6 & 3,717 & 1,905 & 3.7 \\
& $P$-value & 0.02 & 0.01 & 0.50 & 0.09 \\
\hline
\end{tabular}

w Seed treatment: Base $($ control $)=$ base seed treatment by Bayer CropScience with prothioconazole + penflufen + metalaxyl (EverGol Energy, $0.019 \mathrm{mg}$ a.i./seed; Bayer CropScience), metalaxyl (Allegiance, $0.02 \mathrm{mg}$ a.i./seed; Bayer CropScience), and clothianidin + Bacillus firmus (Poncho/VOTiVO, $0.13 \mathrm{mg}$ a.i./seed; Bayer CropScience); fluopyram (ILeVO, $0.15 \mathrm{mg}$ a.i./ seed; Bayer CropScience).

${ }^{x}$ FDX of SDS was calculated as follows: FDX $=$ disease incidence $\times$ disease severity/9. Disease incidence was estimated as percentage of plants with SDS symptoms per plot and disease severity was scored on a 1 to 9 scale $(1=1$ to $10 \%$ leaf surface chlorotic or 1 to $5 \%$ necrotic and $9=$ premature death) based on percentage of the chlorotic and necrotic leaf area and defoliation.

y Pf were counted at the end of season, prior to or within a month after harvest.

z SCN Reproductive factor was calculated as follows: $\mathrm{Rf}=\mathrm{Pf} / \mathrm{Pi}$, where $\mathrm{Pf}=$ postharvest $\mathrm{SCN}$ egg counts and $\mathrm{Pi}=$ initial $\mathrm{SCN}$ egg counts.

Table 4. Main effects of soybean cyst nematode resistance (SCN Res) source for postharvest SCN egg counts (Pf) and SCN reproductive factor (Pf/Pi) in field experiments, performed in Illinois, Indiana, Iowa, Michigan, and Ontario, Canada, in 2013, 2014, and 2015

\begin{tabular}{|c|c|c|c|c|c|c|c|}
\hline \multirow[b]{3}{*}{ Year } & \multirow[b]{3}{*}{ Source of SCN Res } & \multicolumn{3}{|c|}{ Pf } & \multicolumn{3}{|c|}{$\mathbf{R f}^{\mathbf{z}}$} \\
\hline & & \multicolumn{3}{|c|}{ Groupy } & \multicolumn{3}{|c|}{ Group } \\
\hline & & 0- & 2- & $1.2-$ & 0- & 2- & $1.2-$ \\
\hline \multirow[t]{4}{*}{2013} & None & 8,517 & 3,266 a & 8,694 a & 2.2 & $2.9 \mathrm{a}$ & $7.8 \mathrm{a}$ \\
\hline & PI 88788 & 7,163 & 2,946 a & $3,426 \mathrm{~b}$ & 1.6 & $1.8 \mathrm{a}$ & $3.6 \mathrm{~b}$ \\
\hline & Peking & 5,460 & $34 \mathrm{~b}$ & $1,816 \mathrm{c}$ & 1.4 & $0.1 \mathrm{~b}$ & $1.8 \mathrm{~b}$ \\
\hline & $P$-value & 0.22 & $<0.01$ & $<0.01$ & 0.20 & $<0.01$ & $<0.01$ \\
\hline \multirow[t]{4}{*}{2014} & None & 9,002 & $4,126 \mathrm{a}$ & $7,380 \mathrm{a}$ & $\ldots$ & 8.1 & $14.3 \mathrm{a}$ \\
\hline & PI 88788 & 5,853 & $2,222 \mathrm{~b}$ & $3,277 \mathrm{~b}$ & $\ldots$ & 19.8 & $3.5 \mathrm{~b}$ \\
\hline & Peking & 5,742 & $184 \mathrm{c}$ & $807 \mathrm{c}$ & $\ldots$ & -0.2 & $1.5 \mathrm{~b}$ \\
\hline & $P$-value & 0.10 & $<0.01$ & $<0.01$ & $\ldots$ & 0.07 & $<0.01$ \\
\hline \multirow[t]{4}{*}{2015} & None & $10,327 \mathrm{a}$ & $1,763 \mathrm{a}$ & $4,338 \mathrm{a}$ & $7.4 \mathrm{a}$ & 3.2 & $5.6 \mathrm{a}$ \\
\hline & PI 88788 & $3,530 \mathrm{~b}$ & $944 \mathrm{~b}$ & $2,955 \mathrm{~b}$ & $2.1 \mathrm{~b}$ & 2.9 & $3.7 \mathrm{a}$ \\
\hline & Peking & $1,597 \mathrm{c}$ & $102 \mathrm{c}$ & $1,529 \mathrm{c}$ & $1.1 \mathrm{~b}$ & 1.1 & $1.6 \mathrm{~b}$ \\
\hline & $P$-value & $<0.01$ & $<0.01$ & $<0.01$ & $<0.01$ & 0.07 & $<0.01$ \\
\hline
\end{tabular}

${ }^{\mathrm{y}}$ Test locations were grouped based on HG type and locations within each group were combined for analysis.

${ }^{\mathrm{z}} \mathrm{SCN}$ reproductive factor was calculated as follows: $\mathrm{Rf}=\mathrm{Pf} / \mathrm{Pi}$, where $\mathrm{Pf}=$ postharvest $\mathrm{SCN}$ egg counts and $\mathrm{Pi}=$ initial $\mathrm{SCN}$ egg counts . 
across the locations. Further research is needed with more uniform and controlled settings under SCN populations with different HG types.

In our study, yield was negatively correlated with FDX and Pf, which was expected. Previously, mixed results in terms of correlation between yield, SDS, and SCN density have been observed (Hershman et al. 1990; Kandel et al. 2016a). The absence of correlations of yield with SDS and SCN density in a previous study (Hershman et al. 1990) may have occurred because SDS developed relatively late (mid R5 or later) at mild levels and SCN population was low. Additionally, methods for routine quantification of $F$. virguliforme in soil are currently not available (Kandel et al. 2015b; Wang et al. 2015), and should also be noted that there is variation in $F$. virguliforme virulence and genotypes (Li et al. 2009; Wang and Chilvers 2016). Our findings that cultivars with no SCN resistance resulted in the lowest yield along with the highest FDX and SCN density supports previous research that reported SDS and associated yield losses tend to be worse in the presence of SCN (McLean and Lawrence 1993).

Our study showed that year-to-year variation from 2013 to 2015 was significant for SDS, but not for SCN. In 2013, a low level of SDS was observed in many nonirrigated locations, which may be due to the dry conditions during the growing season, especially in July and August that are the critical months for SDS development (Leandro et al. 2013). Moisture level also affects SCN hatching, but SCN does not require the high level of moisture that contributes to SDS. A previous study (Tefft et al. 1982) found $25 \%$ moisture in soil to be optimum for SCN hatching but further increases in moisture resulted in a decline. Thus, the Pf counts in 2013 were not lower than 2014 or 2015 and were even greater in some locations in 2013 than the other two years, whereas SDS was lower in 2013 compared with other years.

Fluopyram did not impact Rf or Pf. This is the first study evaluating efficacy of fluopyram seed treatment on SCN in field conditions over multiple locations and years. This was contrary to controlled environment studies that reported reduced hatching and motility of SCN eggs and reduced number of eggs and cysts with fluopyram seed treatment (Beeman and Tylka 2015). These differences may be associated with the greater variation in field, difference in inoculum level, difference in cultivars, presence of other fungal pathogens etc. However, yield was increased with fluopyram seed treatment compared with a base seed treatment in both years it was tested, including 2014, when FDX did not significantly differ between seed treatments. Increased yield could also have been due to reduced root rot in fluopyram treated plots, as reported in previous studies (Kandel et al. 2016a, b). In 2015, the effect of fluopyram on FDX was more pronounced when FDX was greater than 10, similar to the findings of Kandel et al. (2016a).

This study documents a shift in SCN population over a large geographic area, which may impact SDS severity and yield of soybean cultivars with PI 88788-type resistance. Our results emphasize the importance of using cultivars with different sources of SCN resistance,

Table 6. Correlation among foliar disease index (FDX) of sudden death syndrome (SDS), postharvest soybean cyst nematode (SCN) egg counts ( $\mathrm{Pf}$ ), and yield observed in field experiments carried out in Illinois, Indiana, Iowa, Michigan, and Ontario, Canada, in 2013 to 2015

\begin{tabular}{lrcr}
\hline & \multicolumn{3}{c}{ Pearson correlation coefficient $^{\mathbf{z}}$} \\
\cline { 2 - 4 } Factor $^{\mathbf{y}}$ & $\mathbf{2 0 1 3}$ & $\mathbf{2 0 1 4}$ & $\mathbf{2 0 1 5}$ \\
\hline FDX - Pf & 0.31 & 0.31 & 0.18 \\
FDX - Yield & -0.23 & -0.34 & -0.52 \\
Yield - Pf & -0.37 & -0.35 & -0.40 \\
\hline
\end{tabular}

y FDX of SDS was calculated as follows: FDX $=$ disease incidence $\times$ disease severity/9. Disease incidence was estimated as percentage of plants with SDS symptoms per plot and foliar disease severity was scored as the average disease severity of symptomatic plants per plot on a 1 to 9 scale where $1=1$ to $10 \%$ leaf surface chlorotic or 1 to $5 \%$ necrotic and $9=$ premature plant death. Pf was counted at the end of season, prior to or within a month after harvest.

${ }^{\mathrm{z}}$ All correlation coefficients were statistically significant with $P$-values $<0.01$. which has previously been suggested (Mitchum 2016; Wise et al. 2016). Farmers are advised to not only sample fields to know SCN field population concentrations, but also determine the HG type of $\mathrm{SCN}$ in each field to determine if cultivars with a source of resistance other than PI 88788 are needed. Besides Peking, other sources of resistance such as PI 437654 were still effective against all of the tested SCN populations, and these sources of resistance can be used to develop SCN-resistant cultivars. SCN management could reduce SDS, but farmers should not rely on SCN resistance for SDS management. Fluopyram seed treatment reduces SDS, but did not reduce SCN in this study, and may not be an effective treatment for SCN.

\section{Acknowledgments}

Partial funding for this study was provided by Bayer CropScience and soybean checkoff through the North Central Soybean Research Program in the United States, and the Grain Farmers of Ontario in Canada, which was funded through Ontario Farm Innovation Program, a component of Growing Forward 2. We thank D. Sjarpe, A. Haafke, and G. Han from Iowa State University; N. Anderson, J. Leuck, and J. Ravellette from Purdue University; K. Ames from the University of Illinois; F. Warner, J. F. Boyse, and R. Laurenz from Michigan State University; C. Van Herk and G. Kotulak from Ontario Ministry of Agriculture Food and Rural Affairs for their assistance with trial establishment, maintenance, and data collection. We would also like to thank J. Batzer and G. Tylka for reviewing this manuscript.

\section{Literature Cited}

Acharya, K., Tande, C., and Byamukama, E. 2016. Determination of Heterodera glycines virulence phenotypes occuring in South Dakota. Plant Dis. 100: 2281-2286.

Aoki, T., O'donnell, K., Homma, Y., and Lattanzi, A. R. 2003. Sudden death syndrome of soybean is caused by two morphologically and phylogenetically distinct species within the Fusarium solani species complex-F. virguliforme in North America and F. tucumaniae in South America. Mycologia 95:660-684.

Beeman, A., and Tylka, G. L. 2015. Effects of ILeVO and VOTiVO seed treatments on hatching, motility, and root penetration of the soybean cyst nematode. Phytopathology 105:S4.14.

Bradley, C. A., Allen, T., and Esker, P. 2014. Estimates of soybean yield reductions caused by diseases in the United States. Ext. and Outreach, Dept. of Crop Sci., Univ. of Illinois, Champaign-Urbana. Retrieved on 19 December 2016 from http://extension.cropsciences.illinois.edu/fieldcrops/diseases/ yield_reductions.php

Brucker, E., Niblack, T., Kopisch-Obuch, F. J., and Diers, B. W. 2005. The effect of rhg1 on reproduction of Heterodera glycines in the field and greenhouse and associated effects on agronomic traits. Crop Sci. 45:1721-1727.

Concibido, V. C., Diers, B. W., and Arelli, P. R. 2004. A decade of QTL mapping for cyst nematode resistance in soybean. Crop Sci. 44:1121-1131.

de Farias Neto, A. L., Hartman, G. L., Pedersen, W. L., Li, S., Bollero, G. A., and Diers, B. W. 2006. Irrigation and inoculation treatments that increase the severity of soybean sudden death syndrome in the field. Crop Sci. 46: 2547-2554.

Faghihi, J., and Ferris, J. M. 2000. An efficient new device to release eggs from Heterodera glycines. J. Nematol. 32:411-413.

Faghihi, J., Ferris, V., Donald, P. A., Noel, G. R., and Welacky, T. 2008. Changes in resistance of PI 88788 to field population of soybean cyst nematode (SCN). Pages 50-51 in: Proc. of the 4th Nat'l Soybean Cyst Nematode Conf., Tampa, FL.

Fehr, W. R., Caviness, C. E., Burmood, D. T., and Pennington, J. S. 1971. Stage of development descriptions for soybeans, Glycine max (L.). Merrill. Crop Sci. 11:929-931.

Gao, X., Jackson, T. A., Hartman, G. L., and Niblack, T. L. 2006. Interactions between the soybean cyst nematode and Fusarium solani f. sp. glycines based on greenhouse factorial experiments. Phytopathology 96:1409-1415.

Gerdemann, J. W. 1955. Relation of a large soil-borne spore to phycomycetous mycorrhizal infections. Mycologia 47:619-632.

Gibson, P. T., Shenaut, M. A., Njiti, V. J., Suttner, R. J., and Myers, O., Jr. 1994 Soybean varietal response to sudden death syndrome. Am. Seed Trade Assoc. 24th Soybean Res. Conf. 24:20-40.

Hartman, G. L., Chang, H. X., and Leandro, L. F. 2015a. Research advances and management of soybean sudden death syndrome. Crop Prot. 73: 60-66.

Hartman, G. L., Leandro, L. F. S., and Rupe, J. C. 2015b. Sudden death syndrome. Pages 88-90 in: Compendium of Soybean Diseases and Pests. G. L. Hartman, J. C. Rupe, E. F. Sikora, L. L. Domier, J. A. Davis, and K. L. Steffey, eds. American Phytopathological Society, St. Paul, MN.

Hershman, D., Hendrix, J., Stuckey, R., Bachi, P., and Henson, G. 1990. Influence of planting date and cultivar on soybean sudden death syndrome in Kentucky. Plant Dis. 74:761-766.

Hershman, D. E., Heinz, R. D., and Kennedy, B. S. 2008. Soybean cyst nematode, Heterodera glycines, populations adapting to resistant soybean cultivars in Kentucky. Plant Dis. 92:1475. 
Kandel, Y. R., Bradley, C. A., Wise, K. A., Chilvers, M. I., Tenuta, A. U., Davis, V. M., Esker, P. D., Smith, D. L., Licht, M. A., and Mueller, D. S. 2015a. Effect of glyphosate application on sudden death syndrome of glyphosate-resistant soybean under field conditions. Plant Dis. 99:347-354.

Kandel, Y. R., Haudenshield, J., Srour, A. Y., Islam, K. T., Fakhoury, A. M., Santos, P., Wang, J., Chilvers, M. I., Hartman, G., Malvick, D., Floyd, C. M., Mueller, D., and Leandro, L. F. S. 2015b. Multi-laboratory comparison of quantitative PCR assays for detection and quantification of Fusarium virguliforme from soybean roots and soil. Phytopathology 105:1601-1611.

Kandel, Y. R., Wise, K. A., Bradley, C. A., Chilvers, M. I., Tenuta, A. U., and Mueller, D. S. 2016a. Fungicide and cultivar effects on sudden death syndrome and yield of soybean. Plant Dis. 100:1339-1350.

Kandel, Y. R., Wise, K. A., Bradley, C. A., Tenuta, A. U., and Mueller, D. S. 2016 b. Effect of planting date, seed treatment, and cultivar on plant population, sudden death syndrome, and yield of soybean. Plant Dis. 100:1735-1743.

Leandro, L. F. S., Robertson, A. E., Mueller, D. S., and Yang, X. B. 2013. Climatic and environmental trends observed during epidemic and non-epidemic years of sudden death syndrome In Iowa. Plant Health Prog. doi:10.1094/PHP-20130529-01-RS

Li, S., Hartman, G., and Chen, Y. 2009. Evaluation of aggressiveness of Fusarium virguliforme isolates that cause soybean sudden death syndrome. J. Plant Pathol. 91:77-86.

Marburger, D., Conley, S., and Gaska, J. 2013. The relationship between the causal agent of SDS and SCN in Wisconsin. Coop. Ext., Univ. of Wisconsin, Madison. http://fyi.uwex.edu/fieldcroppathology/files/2013/12/SCN_SDS_2013_FINAL.pdf.

McLean, K. S., and Lawrence, G. W. 1993. Interrelationship of Heterodera glycines and Fusarium solani in sudden death syndrome of soybean. J. Nematol. 25:434-439.

Melgar, J., Roy, K. W., and Abney, T. S. 1994. Sudden death syndrome of soybean: etiology, symptomatology, and effects of irrigation and Heterodera glycines on incidence and severity under field conditions. Can. J. Bot. 72: 1647-1653.

Mitchum, M. G. 2016. Soybean resistance to the soybean cyst nematode Heterodera glycines: An update. Phytopathology 106:1444-1450.

Mitchum, M. G., Wrather, J. A., Heinz, R. D., Shannon, J. G., and Danekas, G. 2007. Variability in distribution and virulence phenotypes of Heterodera glycines in Missouri during 2005. Plant Dis. 91:1473-1476.

Niblack, T. L. 2005. Soybean cyst nematode management reconsidered. Plant Dis. 89:1020-1026.

Niblack, T. L., Arelli, P. R., Noel, G. R., Opperman, C. H., Orf, J. H., Schmitt, D. P., Shannon, J. G., and Tylka, G. L. 2002. A revised classification scheme for genetically diverse populations of Heterodera glycines. J. Nematol. 34:279-288.

Powell, N. T. 1971. Interactions between nematodes and fungi in disease complexes. Annu. Rev. Phytopathol. 9:253-274.

Roy, K., Hershman, D., Rupe, J., and Abney, T. 1997. Sudden death syndrome of soybean. Plant Dis. 81:1100-1111.

Roy, K., Lawrence, G., Hodges, H., Mclean, K., and Killebrew, J. 1989. Sudden death syndrome of soybean: Fusarium solani as incitant and relation of Heterodera glycines to disease severity. Phytopathology 79:191-197.

Rzodkiewicz, P. A. 2010. Characterization of soybean cyst nematode diversity in Kansas. M.S. thesis. Kansas State Univ., Manhattan, KS.
Scherm, H., Yang, X., and Lundeen, P. 1998. Soil variables associated with sudden death syndrome in soybean fields in Iowa. Plant Dis. 82:1152-1157.

Tabor, G. M., Tylka, G. L., Behm, J. E., and Bronson, C. R. 2003. Heterodera glycines infection increases incidence and severity of brown stem rot in both resistant and susceptible soybean. Plant Dis. 87:655-661.

Tabor, G. M., Tylka, G. L., and Bronson, C. R. 2006. Soybean stem colonization by genotypes $\mathrm{A}$ and $\mathrm{B}$ of Cadophora gregata increases with increasing population densities of Heterodera glycines. Plant Dis. 90:1297-1301.

Tatalović, N. 2014. Influence of Heterodera glycines infection, plant age and water availability on foliar symptoms of sudden death syndrome, root symptom severity and root morphology of soybean plants infected by Fusarium virguliforme. $\mathrm{Ph} . \mathrm{D}$. dissertation, Iowa State University, Ames, IA.

Tefft, P. M., Rende, J. F., and Bone, L. W. 1982. Factors influencing egg hatching of the soybean cyst nematode Heterodera glycines Race 3. Helminthol. Soc. Wash. 49:258-265.

Tylka, G. L., and Marett, C. C. 2014. Distribution of the soybean cyst nematode, Heterodera glycines, in the United States and Canada: 1954 to 2014. Plant Health Prog. doi:10.1094/PHP-BR-14-0006.

Tylka, G. L., and Mullaney, M. P. 2015. Soybean cyst nematode-resistant soybean varieties for Iowa. Coop. Ext. Publ. PM 1649. Iowa State Univ., Ames, IA Online publication. https://store.extension.iastate.edu/Product/Soybean-cystnematode-resistant-soybean-varieties-for-Iowa-pdf

Wang, J., and Chilvers, M. I. 2016. Development and characterization of microsatellite markers for Fusarium virguliforme and their transferability to clade 2 of the Fusarium solani species complex. Fungal Ecol. 20:7-14.

Wang, J., Donald, P. A., Niblack, T. L., Bird, G. W., Faghihi, J., Ferris, J. M., Grau, C., Jardine, D. J., Lipps, P. E., Macguidwin, A. E., Melakeberhan, H., Noel, G. R., Pierson, P., Riedel, R. M., Sellers, P. R., Stienstra, W. C., Todd, T. C., Tylka, G. L., Wheeler, T. A., and Wysong, D. S. 2000. Soybean cyst nematode reproduction in the north central United States. Plant Dis. 84:77-82.

Wang, J., Jacobs, J. L., Byrne, J. M., and Chilvers, M. I. 2015. Improved diagnoses and quantification of Fusarium virguliforme, causal agent of soybean sudden death syndrome. Phytopathology 105:378-387.

Wise, K. A., Faghihi, J., and Ferris, V. R. 2016. Effect of soybean cyst nematoderesistant cultivars on an HG type 2 population of Heterodera glycines and sudden death syndrome in Indiana soybean. Crop, Forage, Turfgrass Manage. doi:10.2134/cftm2016.0009

Wrather, J. A., Shannon, G., Balardin, R., Carregal, L., Escobar, R., Gupta, G. K. Ma, Z., Morel, W., Pioper, D., and Tenuta, A. 2010. Effect of diseases on soybean yield in the top eight producing countries in 2006. Plant Health Prog. doi:10.1094/PHP-2010-0125-01-RS.

Xing, L., and Westphal, A. 2006. Interaction of Fusarium solani f. sp. glycines and Heterodera glycines in sudden death syndrome of soybean. Phytopathology 96:763-770.

Xing, L., and Westphal, A. 2013. Synergism in the interaction of Fusarium virguliforme with Heterodera glycines in sudden death syndrome of soybean. J. Plant Dis. Prot. 120:209-217.

Zaworski, E. R. 2014. Effects of ILeVO on soybean sudden death syndrome and soybean cyst nematode. M.S. Thesis, Iowa State Univ., Ames, IA.

Zheng, J., Li, Y., and Chen, S. 2006. Characterization of the virulence phenotypes of Heterodera glycines in Minnesota. J. Nematol. 38:383-390. 